\title{
POSIÇÃO DA SEMENTE NA SEMEADURA E TIPO DE SUBSTRATO SOBRE A EMERGÊNCIA E CRESCIMENTO DE PLÂNTULAS DE Schizolobium parahyba (Vell.) S.F. Blake
}

\author{
EFFECT OF THE SEED SOWING POSITION AND TYPE OF SUBSTRATE ON THE EMERGENCE \\ AND GROWTH OF SEEDLINGS OF Schizolobium parahyba (Vell.) S.F. Blake
}

\author{
Cibele Chalita Martins ${ }^{1}$ Anderson da Silva Borges ${ }^{2}$ \\ Maria Renata Rocha Pereira ${ }^{3}$ Maria Teresa Gomes Lopes ${ }^{4}$
}

\begin{abstract}
RESUMO
A germinação rápida e uniforme das sementes, seguida por pronta emergência das plântulas são características altamente desejáveis na formação de mudas. O objetivo deste trabalho foi identificar a posição da semente na semeadura e o substrato mais adequado ao processo de germinação e crescimento de plântulas de Schizolobium parahyba (Vell.) S.F. Blake. As sementes foram colocadas para germinar nas seguintes posições em relação ao fundo do sulco no substrato: semente com o hilo voltado para cima, com o hilo voltado para baixo, apoiada sobre uma das faces, semente de lado sobre a espessura e faces paralelas às paredes do saquinho. Os substratos utilizados foram: substrato comercial Plantmax ${ }^{\circledR}$ (testemunha), serragem de pinus e areia. Os tratamentos foram dispostos no delineamento inteiramente casualizado em arranjo fatorial $4 \times 3$ (posições da semente $\mathrm{x}$ substrato) com quatro repetições de 20 sementes. Os parâmetros avaliados foram porcentagem de emergência, morte de plântulas após a emergência, primeira contagem, índice de velocidade de emergência e comprimento da parte aérea das plântulas. Conclui-se que todas as posições de semeadura adotadas em substrato serragem de pinus oferecem as condições mais adequadas ao processo de germinação e crescimento de plântulas de Schizolobium parahyba.
\end{abstract}

Palavras-chave: germinação; vigor; mudas; guapuruvu.

\section{ABSTRACT}

Rapid and uniform germination of seeds followed by prompt emergence are highly desirable characteristics for the production of seedlings. The aim of this study was to identify sowing positions and types of substrate most likely to the seed germination process and growth of seedlings of Schizolobium parahyba (Vell.) S.F. Blake. To germinate the seeds, they were placed in the following positions in relation to the bottom of the furrow in the substrate: hilum uppermost, hilum at the bottom, supported on one side, seed on edge with its sides parallel to the walls of the bag. Three substrates were used: commercial plantmax substrate (control), pine sawdust and sand. The substrates were fully randomized in a $4 \times 3$ factorial design (four seed positions and three substrates), with four replications of 20 seeds. The parameters evaluated were: the percentage of emergence, the after emergence seedling deaths, the first-count test, the emergence speed index, and the seedling aerial part length. It was concluded that all the seed positions in pine sawdust sowing offer the more favorable conditions for the germination process and seedling growth of Schizolobium parahyba.

Keywords: germination; vigor; seedling; guapuruvu.

1. Engenheira Agrônoma, Dra., Professora assistente de doutor. Universidade Estadual Paulista, Faculdade de Ciências Agrárias e Veterinárias de Jaboticabal, Via Acesso Prof. Paulo Donato Castellane, s/n, CEP 14884-900, Jaboticabal (SP).cibele@fcav.unesp.br.

2. Tecnólogo em Silvicultura, Faculdade de Tecnologia do Estado de São Paulo, Curso superior de Tecnologia em Silvicultura, Rua Amantino de Oliveira Ramos, 60, CEP 18300-000, Capão Bonito (SP). anderson5borges@rocketmail.com

3. Engenheira Florestal, Pós-doutoranda do Curso de Irrigação e Drenagem, Universidade Estadual Paulista, Caixa Postal 237, CEP 18610-307, Botucatu (SP). mariarenata10@hotmail.com

4. Engenheira Agrônoma, Dra., Professora Adjunta, Faculdade de Ciências Agrárias, Universidade Federal do Amazonas, Av. Gen. Rodrigo Octávio Jordão Ramos, 3000, Campus Universitário, CEP 69077-000, Manaus (AM).mtglopes@ufam.edu.br

Recebido para publicação em 8/03/2011 e aceito em 29/08/2011 


\section{INTRODUÇÃO}

O guapuruvu ou ficheira (Schizolobium parahyba (Vell.) S.F. Blake) é uma espécie nativa da família Fabaceae (BARNEBY, 1996), de rápido crescimento e característica da Floresta Ombrófila Densa (Floresta Atlântica), ocorrendo principalmente em planícies aluviais, ao longo de rios e no início de encostas (CARVALHO, 2003). Sua nítida preferência por locais mais úmidos a classifica como uma seletiva higrófita (LORENZI, 1992). A madeira desta espécie é bastante utilizada para produção de compensados, brinquedos e caixotaria leve (RIZZINI, 1972; LORENZI, 1992).

Segundo Bianchetti e Ramos (1981), as árvores desta espécie podem atingir até $30 \mathrm{~m}$ de altura (no mínimo $10 \mathrm{~m}$ ), com diâmetro a altura do peito entre 30 e $60 \mathrm{~cm}$, com copa de 6 a $10 \mathrm{~m}$ de diâmetro e forma larga e arredondada. Por tratar-se de espécie de rápido crescimento, é recomendada para fins ornamentais, para programas de reflorestamento e projetos de recuperação de áreas degradadas (RIZZINI, 1972; LORENZI, 1992).

A atividade de produção de mudas em viveiro é de suma importância no setor florestal, bem como pesquisas de melhoramento e desenvolvimento de novas técnicas para a produção de mudas. A rapidez e uniformidade da germinação são características desejáveis na formação de mudas, pois quanto mais tempo a plântula permanece nos estádios iniciais de desenvolvimento mais tempo fica sujeita às condições adversas do ambiente (MARTINS et al., 1999). A demora na germinação também contribui para o aumento dos custos de produção de mudas no viveiro, necessitando de mão de obra, irrigação e cuidados por mais tempo. Além da intensidade de dormência, a velocidade de germinação também pode ser influenciada pelo vigor da semente, temperatura, umidade, textura do substrato, profundidade e posição da semente no substrato, dentre outros fatores (MARTINS et al., 1999; CARVALHO e NAKAGAWA, 2000; NASCIMENTO et al., 2002; ELIAS et al., 2006).

As sementes de guapuruvu são relativamente grandes, contabilizando-se aproximadamente 500 unidades por quilo e apresentam dormência devido à impermeabilidade do tegumento à água (BIANCHETTI e RAMOS, 1981). A escarificação mecânica pode ser utilizada para a promoção da germinação que ocorre de 8 a 15 dias após a semeadura em sementes com a dormência superada (BIANCHETTI e RAMOS, 1981).
A posição da semente na semeadura pode ser um fator que reduz o tempo de permanência das mudas no viveiro, pois o processo de germinação requer a realização de movimentos rotatórios dos cotilédones sob o solo dependendo da sua posição e algumas posições podem facilitar ou dificultar a emergência das plântulas (CARVALHO e NAKAGAWA, 2000); isto foi constatado para sementes de Euterpe espiritosantensis Fernades (MARTINS et al., 1999), Oenocarpus mapora Karsten (NASCIMENTO et al., 2002), Astrocaryum aculeatum G. Mey. (ELIAS et al., 2006) e Anacardium occidentale L. (ARAUJO et al., 2009).

A produção de mudas em viveiros vem crescendo anualmente, com isso a necessidade de utilização de vários tipos de substratos para a produção de mudas de espécies nativas e exóticas. Os substratos têm a função de servir de suporte para a muda, favorecer o desenvolvimento do sistema radicular, possibilitar a formação de um torrão firme, ter capacidade de retenção de nutrientes e umidade (NAPPO et al., 2001). Para a germinação e desenvolvimento da plântula, devem ser consideradas características do substrato como porosidade, retenção da água e susceptibilidade a patógenos (BRASIL, 2009; MARTINS et al., 2012).

A escolha do substrato deve ser feita em função das exigências da semente, em relação ao seu tamanho, formato, entre outros. A areia é um substrato recomendado para o teste de germinação e apresenta bons resultados para a produção de mudas de guapuruvu (COELHO et al., 2006; BRASIL, 2009). Existem substratos produzidos em escala industrial como o Plantmax ${ }^{\circledR}$ florestal, tradicionalmente utilizado por viveiros para a produção de mudas; este substrato apresenta na sua formulação casca de pinus, vermiculita, turfa, calcário e adubo químico.

No entanto, existem resíduos e subprodutos da atividade madeireira que podem ser utilizados como substrato e diminuir os custos de produção, tais como a casca de pinus e a serragem (MARTINS et al., 2012). Estudos com a finalidade de viabilizar a utilização destes substratos representam uma demanda atual, pois os sistemas de produção são favorecidos pelo uso de insumos regionais e de baixo custo (MAEDA et al., 2007). A serragem de pinus constitui um dos resíduos da atividade madeireira, costuma ser deixado em áreas de descarte sobre o solo próximo a serrarias apresentando riscos de combustão, lenta degradação e altos índices de cálcio e magnésio, (MAEDA et al., 2007; NÓBREGA et 
al., 2007).

Assim, o objetivo deste trabalho foi identificar a posição da semente na semeadura e o substrato mais adequado ao processo de germinação e crescimento de plântulas de Schizolobium parahyba (Vell.) S.F. Blake.

\section{MATERIAL E MÉTODOS}

As sementes de Schizolobium parahyba (Vell.) S.F. Blake foram coletadas no mês de junho de 2010 no município de Capão Bonito, SP, em 11 matrizes, na quantidade de aproximadamente meio quilo de sementes por planta. As árvores matrizes foram selecionadas com base em aspectos visuais de porte e vigor(altura ediâmetro superior, dominância)e sanidade. As sementes foram extraídas manualmente das vagens e submetidas à limpeza para a retirada de sementes chochas, malformadas e danificadas por fungos e insetos. Antes da semeadura as sementes foram submetidas à escarificação mecânica para a superação da dormência com uma lixa industrial (esmeril) no sentido longitudinal da semente, para evitar danos ao eixo embrionário.

Foram avaliadas quatro posições de semeadura em relação à superfície do substrato, esquematizadas na Figura 1: A (semente em pé com o hilo para cima); B (semente em pé com o hilo para baixo); C (semente sobre uma das faces); D (semente plantada de lado sobre a espessura e faces paralelas às paredes do saquinho) e foram avaliados três substratos para a produção de mudas: substrato comercial Plantmax ${ }^{\circledR}$ florestal, areia fina e casca de pinus moída. Os substratos foram colocados em sacos de polietileno perfurado de $0,5 \mathrm{~L}$. A semeadura foi realizada a $4 \mathrm{~cm}$ de profundidade e para cada tratamento foram utilizadas quatro repetições de 20 sementes.

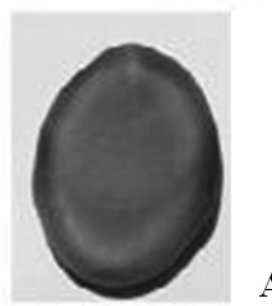

A
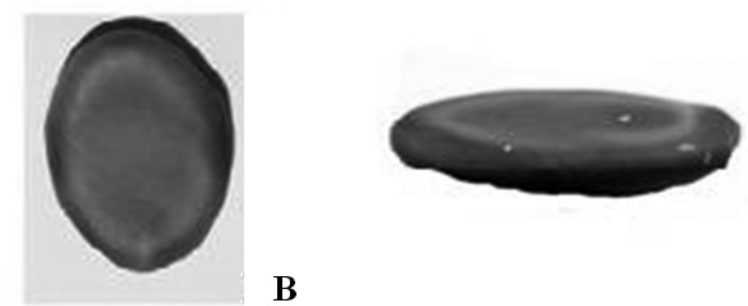

B
Após a semeadura, as mudas permaneceram em viveiro localizado no Instituto de Pesquisa Ecológica (IPE), no município de Buri, SP, latitude $23^{\circ} 45^{\prime} 42.18^{\prime \prime}$ S e longitude $48^{\circ} 36^{\prime} 34.85^{\prime \prime} \mathrm{O}$, situado a $682 \mathrm{~m}$ de altitude. $\mathrm{O}$ viveiro apresentava piso de brita, estrutura de madeira recoberta com telado de polietileno com nível de sombreamento de $50 \%$ e bancadas para sacos plásticos com $1 \mathrm{~m}$ de largura suspensas a $0,80 \mathrm{~m}$ acima do piso. As temperaturas médias mínimas e máximas vigentes durante o período experimental foram de $23,3{ }^{\circ} \mathrm{C}$ e $12,3{ }^{\circ} \mathrm{C}$, respectivamente. A irrigação foi realizada com regador de crivo fino, diariamente, ao início da manhã.

Para avaliar o efeito dos tratamentos na qualidade da semente e no desempenho das plântulas, foram utilizados os seguintes testes:

Emergência de plântulas em substrato - A contagem das plântulas foi realizada, em intervalos de 3 dias do $3^{\circ}$ ao $14^{\circ}$ dia após a semeadura. Considerou-se plântula emersa, aquela com parte do hipocótilo visível fora do substrato.

Primeira contagem - realizada conjuntamente com a emergência de plântulas, registrando-se a porcentagem de plântulas normais presentes no terceiro dia após a semeadura. As plântulas normais são caracterizadas por apresentar todas as estruturas essenciais completas, sadias e proporcionais ou danificações que não comprometam seu desenvolvimento; essas plântulas têm potencial para continuar seu desenvolvimento e dar origem a plantas sob condições favoráveis de campo (BRASIL, 2009).

Índice de Velocidade de Emergência (IVE) - determinado por meio de critérios estabelecidos por Maguire (1962), contabilizando-se as plântulas normais emersas do substrato até 14 dias

FIGURA 1: Posição de semeadura: semente com o hilo voltado para cima (A), com o hilo voltado para baixo (B), apoiada sobre uma das faces (C), semente plantada de lado sobre a espessura e faces paralelas às paredes do saquinho (D).

FIGURE 1: Sowing positions: seed with hilum uppermost (A), with hilum at the bottom (B), supported on one side $(C)$, seed on edge with sides parallel to the walls of the bag (D). 
da semeadura.

Comprimento da parte aérea das plântulas (CP) - foi avaliado o comprimento (mm) da parte aérea das plântulas com auxílio de uma régua, semanalmente, dos 14 aos 49 dias após a semeadura.

Morte de plântulas após a emergência - determinado pela diferença entre a porcentagem de plântulas presentes no substrato aos 14 dias e 49 dias.

A análise de variância foi realizada para cada avaliação no delineamento experimental inteiramente casualizado, num esquema fatorial $4 \mathrm{x}$ 3 (posições de semeadura x substratos), com quatro repetições conforme instalação do experimento. A comparação entre as médias dos tratamentos foi efetuada pelo teste de Tukey $(\mathrm{p}>0,05)$. Os dados expressos em porcentagem foram transformados em arco seno $(\mathrm{x} / 100)^{1 / 2} \mathrm{e}$ as médias apresentadas nas tabelas são dos dados originais.

\section{RESULTADOS E DISCUSSÃO}

Na Tabela 1 foramapresentados os resultados da análise de variância dos dados referentes à emergência de plântulas, primeira contagem, índice de velocidade de emergência e morte de plântulas após a emergência devido à posição da semente na semeadura e tipo de substrato utilizado na produção de mudas.

A porcentagem final de emergência das plântulas para todos os substratos e posições das sementes avaliadas, assim como o vigor das sementes e a velocidade de emergência de plântulas de guapuruvu avaliados pelos testes da primeira contagem e índice de velocidade de emergência
(IVE) foram similares apresentando valores médios de $46,1 \%$; 3,2 e $72 \%$ (Tabelas 1 e 2); portanto, os fatores estudados não afetaram o processo de germinação.

Estes resultados divergem dos obtidos para sementes de Euterpe espiritosantensis Fernades (MARTINS et al., 1999), Oenocarpus mapora Karsten (NASCIMENTO et al., 2002), Astrocaryum aculeatum G. Mey. (ELIAS et al., 2006), indicando que a importância do efeito da posição da semente sobre a geminação e vigor depende da espécie a ser estudada. Araújo et al. (2009) verificaram influência da posição da semeadura sobre a velocidade de emergência de Anacardium occidentale L., mas não sobre a porcentagem final de germinação. Laime et al. (2010) observaram que, em sementes de Inga ingoides (Rich.) Willd. semeadas com o hilo para baixo, diminui o IVE e a porcentagem de emergência na primeira contagem, já, na porcentagem de emergência total, sementes posicionadas com o hilo para cima obtiveram os menores resultados. Para sementes de Amburana cearenses, a semeadura deve ser com o hilo de lado, formando um ângulo de $90^{\circ} \mathrm{em}$ relação ao eixo perpendicular ao nível do substrato para promover maior emergência e vigor das plântulas (GUEDES et al., 2010).

Nas Tabelas 1 e 2 verificou-se efeito do substrato e da interação substrato e posição de semeadura sobre a sobrevivência ou morte das plântulas após a emergência. A semeadura com o hilo para cima em areia causou aproximadamente $56 \%$ de morte após a emergência, valor significativamente maior que as semeadas na mesma posição em substrato comercial ou pinus, e também às semeadas em areia, mas em outras posições.

Ao se avaliarem as diferentes posições da

TABELA 1: Resultados da análise de variância da emergência de plântulas, primeira contagem, índice de velocidade de emergência (IVE) e morte de plântulas após a emergência de Schizolobium parahyba semeada em diferentes substratos e posições de semente.

TABLE 1: Analysis of variance results for seedling emergence, first-count test, the emergence speed index (IVE), and seedling mortality after emergence for Schizolobium parahyba sown on different substrates and with different seed positions.

\begin{tabular}{lcccc}
\hline $\begin{array}{l}\text { Fator de } \\
\text { variação }\end{array}$ & Emergência & $\begin{array}{c}\text { Primeira } \\
\text { contagem }\end{array}$ & IVE & Morte de plântulas \\
\hline F $(\mathrm{S})$ & $1,722^{\text {ns }}$ & $2,099^{\text {ns }}$ & $2,242^{\text {ns }}$ & $9,868^{* *}$ \\
F (P) & $0,842^{\text {ns }}$ & $3,217^{\text {ns }}$ & $1,452^{\text {ns }}$ & $0,024^{\text {ns }}$ \\
F (SXP) & $0,69^{\text {ns }}$ & $0,392^{\text {ns }}$ & $0,559^{\text {ns }}$ & $7,112^{* *}$ \\
\hline CV $(\%)$ & 11,7 & 18,73 & 11,41 & 46,9 \\
\hline
\end{tabular}

Em que: $* *=$ valor significativo pelo teste " $\mathrm{F} "(\mathrm{p} \leq 0,01) ;{ }^{\text {ns }}=$ não significativo 
TABELA 2: Emergência de plântulas, primeira contagem, Índice de velocidade de emergência (IVE) e morte de plântulas após a emergência de Schizolobium parahyba semeada em diferentes substratos e nas posições de semente (A) hilo voltado para cima, (B) hilo voltado para baixo, (C) semente apoiada sobre uma das faces, (D) semente plantada de lado sobre a espessura e faces paralelas às paredes do saquinho.

TABLE 2: Seedling emergence, first-count test, emergence speed index (IVE), and mortality after emergence of seedlings of Schizolobium parahyba sown on different substrates and with different seed positions (A) hilum uppermost, (B) hilum at the bottom, (C) supported on one side, (D) seed on edge with its sides parallel to the walls of the bag.

\begin{tabular}{|c|c|c|c|c|c|c|c|c|c|}
\hline \multirow[b]{2}{*}{$\begin{array}{l}\text { Parâmetros } \\
\text { Avaliados }\end{array}$} & \multirow[b]{2}{*}{ Substratos } & \multicolumn{8}{|c|}{ Posição da semente } \\
\hline & & A & & B & & & & D & \\
\hline \multirow{3}{*}{$\begin{array}{c}\text { Emergência } \\
(\%)\end{array}$} & Comercial & 73,3 & a A & 65,0 & a A & 73,3 & a A & 68,3 & a A \\
\hline & Areia & 78,3 & a A & 73,3 & a A & 73,3 & a A & 76,8 & a A \\
\hline & Pinus & 75,0 & a A & 75,0 & a A & 70,0 & a A & 66,7 & a A \\
\hline \multirow{3}{*}{$\begin{array}{c}\text { Primeira } \\
\text { Contagem (\%) }\end{array}$} & Comercial & 46,65 & a A & 36,65 & $\mathrm{aA}$ & 41,67 & a A & 46,67 & a A \\
\hline & Areia & 51,65 & a A & 40,00 & a A & 53,32 & a A & 51,67 & a A \\
\hline & Pinus & 48,32 & a A & 41,65 & a A & 50,00 & a A & 45,00 & a A \\
\hline \multirow{3}{*}{ IVE } & Comercial & 3,308 & a A & 2,871 & $\mathrm{a} A$ & 3,133 & a A & 3,283 & a A \\
\hline & Areia & 3,496 & a A & 3,150 & a A & 3,496 & a A & 3,467 & a A \\
\hline & Pinus & 3,317 & a A & 3,221 & a A & 2,988 & a A & 3,188 & a A \\
\hline \multirow{3}{*}{$\begin{array}{c}\text { Morte de plântulas } \\
\qquad(\%)\end{array}$} & Comercial & 4,4 & b B & 15,4 & $\mathrm{a} A B$ & 25,1 & $\mathrm{a} A B$ & 31,6 & a A \\
\hline & Areia & 56,6 & a A & 29,5 & a B & 31,9 & a B & 18,4 & a B \\
\hline & Pinus & 10,0 & b A & 25,4 & a A & 16,6 & a A & 22,4 & a A \\
\hline
\end{tabular}

Em que: Médias seguidas de mesma letra minúscula na coluna e maiúscula na linha não diferem entre si pelo teste Tukey $(\mathrm{p}>0,05)$.

semente para cada substrato, verificou-se que a posição da semente no substrato casca de pinus não é importante como causa de morte de plântulas após a emergência, pois os valores foram similares, entre 10 e $25,4 \%$. No entanto, em substrato comercial verificou-se mínima porcentagem de mortalidade de plântulas após a emergência quando a semente foi colocada com hilo para cima e máxima na semeadura com hilo de lado; no substrato comercial, as outras posições apresentaram resultados intermediários e que não diferiram das demais quanto à morte após a emergência de plântulas. Portanto, de modo geral, a colocação da semente com o hilo para cima em substrato comercial ou casca de pinus propiciou as condições mais favoráveis à sobrevivência da semente após a emergência das plântulas, com valores de morte, após as emergências, inferiores a $10 \%$ (Tabela 2).

Nas Tabelas 3 e 4 foram apresentados os resultados da análise de variância e comparação das médias do comprimento de parte aérea de plântulas aos 14 dias, 21 dias, 28 dias, 35 dias, 42 dias e 49 dias após a semeadura, devido à posição da semente e tipo de substrato utilizado na produção de mudas.

O substrato serragem de pinus apresentou os resultados de comprimento de plântulas mais uniformes e independentes das posições de sementes no substrato para cada período de avaliação (Tabelas 3 e 4). Esta uniformidade de desempenho também havia sido verificada para morte de plântulas após a emergência (Tabela 2). Assim, a posição da semente para a semeadura não é importante para a produção de mudas de guapuruvu com serragem de pinus como substrato (Tabelas 2 e 4). De acordo com Souza et al. (2007) as diferentes posições de semeadura (semente com ápice para cima, deitada e ápice para baixo) não influenciaram o comprimento da raiz primária de plântulas de Moringa oleifera $\mathrm{L}$.

De modo oposto, a posição das sementes de Schizolobium parahyba na semeadura teve influência significativa no crescimento de plântulas em substrato comercial e areia, para todos os 
TABELA 3: Resultados da análise de variância do comprimento de parte aérea de plântulas aos 14 dias (CP14), 21 dias (CP21), 28 dias (CP28), 35 dias (CP35), 42 dias (CP42) e 49 dias (CP49) de Schizolobium parahyba semeada em diferentes substratos e posições de semente.

TABLE 3: Analysis of variance results for aerial part length of seedlings at 14 days (CP14), 21 days (CP21), 28 days (CP28), 35 days (CP35), 42 days (CP42) and 49 days (CP49) for Schizolobium parahyba sown on different substrates and with different seed positions.

\begin{tabular}{lcccccc}
\hline Fator de variação & CP14 & CP21 & CP28 & CP35 & CP42 & CP49 \\
\hline F (S) & $17,392^{* *}$ & $23,827^{* *}$ & $36,542^{* *}$ & $28,634^{* *}$ & $36,435^{* *}$ & $37,930^{* *}$ \\
F (P) & $3,516^{*}$ & $13,309^{* *}$ & $8,183^{* *}$ & $10,888^{* *}$ & $14,549^{* *}$ & $15,680^{* *}$ \\
F (SXP) & $15,302^{* *}$ & $25,081^{* *}$ & $32,026^{* *}$ & $30,866^{* *}$ & $33,213^{* *}$ & $35,987 * *$ \\
\hdashline CV (\%) & 13,7 & 5,7 & 4,3 & 3,64 & 3,30 & 3,13 \\
\hline
\end{tabular}

Em que: $* *=$ valor significativo pelo teste " $\mathrm{F} "(\mathrm{p} \leq 0,01) ; *=$ valor significativo pelo teste " $\mathrm{F}$ " $(\mathrm{p} \leq 0,05)$.

TABELA 4: Comprimento ( $\mathrm{mm}$ ) da parte aérea das plântulas de Schizolobium parahyba aos 14, 21, 28, 35, 42 e 49 dias após a semeadura em diferentes substratos e posições de semente: (A) hilo voltado para cima, (B) hilo voltado para baixo, (C) semente apoiada sobre uma das faces, (D) semente plantada de lado sobre a espessura e faces paralelas às paredes do saquinho.

TABLE 4: Aerial part length ( $\mathrm{mm}$ ) of seedlings of Schizolobium parahyba at 14, 21, 28, 35, 42 and 49 days after sowing on different substrates and with different seed positions (A) hilum uppermost, (B) hilum at the bottom, (C) supported on one side, (D) seed on edge with its sides parallel to the walls of the bag.

\begin{tabular}{|c|c|c|c|c|c|c|c|c|c|}
\hline \multirow{2}{*}{$\begin{array}{l}\text { Dias após } \\
\text { Semeadura }\end{array}$} & \multirow[b]{2}{*}{ Substratos } & \multicolumn{8}{|c|}{ Posição da semente } \\
\hline & & & & & & & & & \\
\hline \multirow{3}{*}{14} & Comercial & 10,07 & a A & 10,45 & a A & 7,42 & a B & 7,10 & b B \\
\hline & Areia & 3,72 & $\mathrm{c} \mathrm{C}$ & 5,62 & b BC & 7,30 & a B & 9,72 & a A \\
\hline & Pinus & 7,82 & $\mathrm{~b} A$ & 8,87 & a A & 7,70 & $\mathrm{aA}$ & 8,20 & $\mathrm{ab} A$ \\
\hline \multirow{3}{*}{21} & Comercial & 15,92 & a A & 15,72 & $\mathrm{a} A B$ & 13,32 & $\mathrm{aC}$ & 14,35 & $\mathrm{~b} B C$ \\
\hline & Areia & 10,00 & b D & 11,75 & $\mathrm{~b} C$ & 14,60 & a B & 16,00 & $\mathrm{a} A$ \\
\hline & Pinus & 14,57 & a A & 15,35 & a A & 14,57 & a A & 15,67 & $\mathrm{ab} A$ \\
\hline \multirow{3}{*}{28} & Comercial & 20,12 & $\mathrm{aA}$ & 19,90 & $\mathrm{aA}$ & 17,65 & b B & 18,00 & $\mathrm{bB}$ \\
\hline & Areia & 14,00 & b D & 15,82 & $\mathrm{~b} C$ & 19,35 & a B & 21,00 & a A \\
\hline & Pinus & 20,00 & a A & 20,27 & a A & 19,62 & a A & 20,00 & $\mathrm{a} A$ \\
\hline \multirow{3}{*}{35} & Comercial & 23,20 & a A & 22,90 & $\mathrm{a} A B$ & 20,92 & $\mathrm{~b} B C$ & 21,55 & $\mathrm{bC}$ \\
\hline & Areia & 17,52 & b B & 19,00 & a B & 23,30 & $\mathrm{a} A$ & 23,32 & $\mathrm{aA}$ \\
\hline & Pinus & 23,00 & a A & 23,40 & $\mathrm{a} A$ & 22,90 & a A & 24,20 & $\mathrm{aA}$ \\
\hline \multirow{3}{*}{42} & Comercial & 24,00 & a A & 23,67 & a A & 21,77 & b B & 22,70 & $\mathrm{~b} A B$ \\
\hline & Areia & 18,15 & $\mathrm{bC}$ & 20,20 & b B & 24,15 & $\mathrm{a} A$ & 24,95 & a A \\
\hline & Pinus & 23,65 & a A & 24,80 & b A & 24,00 & a A & 24,15 & a A \\
\hline \multirow{3}{*}{49} & Comercial & 24,27 & a A & 23,90 & $\mathrm{a} A B$ & 22,15 & b C & 22,80 & B BC \\
\hline & Areia & 18,35 & $\mathrm{bC}$ & 20,52 & b B & 24,37 & a A & 25,17 & a A \\
\hline & Pinus & 23,82 & a A & 24,97 & a A & 24,22 & a A & 24,35 & a A \\
\hline
\end{tabular}

Em que: Médias seguidas de mesma letra minúscula na coluna de cada data de medição e maiúscula na linha não diferem entre si pelo teste Tukey $(\mathrm{p}>0,05)$. 
períodos de avaliação (Tabela 4). No substrato areia foram produzidas as menores plântulas, quando a semeadura foi feita com sementes posicionadas com hilo para cima; plântulas de pequenas a médias foram obtidas na semeadura com hilo para baixo; plântulas médias a grandes na semeadura sobre uma das faces da semente $(C)$ e as maiores plântulas foram obtidas na semeadura de lado sobre a espessura e faces paralelas às paredes do saquinho (D). Este efeito tornou-se menos intenso com o passar dos dias após a semeadura, verificando-se diferenças mais evidentes entre as posições em areia aos 14 dias do que aos 49 dias.

Esses resultados corroboram com os obtidos por Guedes et al. (2010) para Amburana cearensis, pois os maiores comprimentos de plântulas foram obtidos para sementes plantadas com hilo de lado e os menores para sementes colocadas no substrato com hilo para cima. No entanto, divergem dos obtidos para sementes de Inga ingoide (LAIME et al., 2010) e Oenocarpus mapora (NASCIMENTO et al., 2002); pois, para essas espécies, a semeadura com hilo para cima resultou nos maiores comprimentos da parte aérea das plântulas. Assim, pode-se inferir que o efeito da posição de semeadura sobre o crescimento das plântulas depende da espécie.

No substrato comercial a influência da posição da semente sobre o comprimento da parte aérea das plântulas foi menos drástica que na areia; foram produzidas as menores plântulas na semeadura com hilo deitado ou de lado e as maiores plântulas na semeadura com hilo para cima ou para baixo.

Assim, verificou-se que a posição da semeadura mais favorável depende do substrato utilizado na produção de mudas: em areia a melhor posição da semente é de lado; em substrato comercial a semente deve ficar de pé, com hilo para cima ou para baixo e para o substrato serragem de pinus qualquer posição pode ser adotada (Tabela 4).

$\mathrm{Na}$ Tabela 4 verifica-se que, inicialmente, aos 14 dias, o substrato comercial possibilitou a produção de plântulas com altura máxima em três das quatro posições estudadas, seguido pela serragem de pinus. No entanto, o desempenho inverteu-se com o passar do tempo; aos 49 dias a serragem de pinus foi o substrato que possibilitou a altura máxima do período, de $24 \mathrm{~cm}$, em média, valor este igual ou superior aos obtidos nos demais substratos.

Assim como um solo, o substrato tem a capacidade de absorver a energia procedente do sol e a quantidade de energia absorvida e retida, respectivamente, dependem da sua cor e da composição química, dentre outros fatores (JORGE, 1985). A absorção e retenção desta energia têm efeito sobre a temperatura do substrato, influenciando a germinação e o crescimento das plântulas. Assim, a casca de pinus e o substrato comercial por serem substratos escuros e com grande porcentagem de matéria orgânica absorvem mais radiação, retêm o calor por mais tempo e apresentam menor variação de temperatura favorecendo o crescimento das plântulas do que aqueles de cores claras e composição à base de sílica, como a areia.

\section{CONCLUSÕES}

Conclui-se que todas as posições de semeadura adotadas em substrato serragem de pinus oferecem as condições mais adequadas ao processo de germinação e crescimento de plântulas de Schizolobium parahyba.

\section{REFERÊNCIAS BIBLIOGRÁFICAS}

ARAUJO, J. R. G. et al. Embebição e posição da semente na germinação de clones de porta-enxertos de cajueiro-anão-precoce. Revista Brasileira Fruticultura, Jaboticabal, v. 31, n. 2, p. 552-558, 2009.

BARNEBY, R. C. Neotropical Fabales at NY: Asides and Oversights. Brittonia, New York, v. 48, n. 2, p. 174-187, 1996.

BIANCHETTI, A.; RAMOS, A. Quebra de dormência de sementes de guapuruvu (Schizolobium parahyba (Vell.) Blake. Boletim de Pesquisa Florestal. Curitiba, n. 3, p. 60-76, 1981. BRASIL.. Ministério da Agricultura, Pecuária e Abastecimento. Secretaria de Defesa Agropecuária. Regras para análise de sementes. Brasília, 2009. $399 \mathrm{p}$.

CARVALHO, N. M.; NAKAGAWA, J. Sementes: Ciência, Tecnologia e Produção. 4. ed. Jaboticabal: FUNEP, 2000. 588 p.

CARVALHO. P. E. R. Espécies Arbóreas Brasileiras. Colombo: Embrapa Florestas, 2003. $1039 \mathrm{p}$.

COELHO, R. R. P. et al. Influência de substratos na formação de mudas de guapuruvu (Schizolobium parahyba (Vell.) Blake). Revista Ciência Agronômica, Fortaleza, v. 37, n. 2, p. 149152, 2006.

ELIAS, M. E. A.; FERREIRA, S. A. N.; GENTIL, 
D. F. O. Emergência de plântulas de tucumã (Astrocaryum aculeatum) em função da posição de semeadura. Acta Amazonica, Manaus, v. 36, n. 3, p. 385-388, 2006.

GUEDES, R. S. et al. Emergência e vigor de plântulas de Amburana cearensis (Allemão) A.C. Smith em função da posição e da profundidade de semeadura. Semina, Londrina, v. 31, n. 4, p. 843-850, 2010.

JORGE, J. A. Física e manejo dos solos tropicais. Campinas: Instituto Campineiro de Ensino Agrícola, 1985. 328 p.

LAIME, E. M. O. et al. Emergência e crescimento inicial de plântulas de Inga ingoides (Rich.) Willd. em função de posições e profundidades de semeadura. Semina, Londrina, v. 31, n. 2, p. 361372, 2010.

LORENZI, H. Árvores brasileiras: manual de identificação cultivo de plantas arbóreas nativas do Brasil; Nova Odessa, SP: Editora Plantarum, 1992. $352 \mathrm{p}$.

MAEDA, S. et al. Caracterização de substratos para produção de mudas de espécies florestais elaborados a partir de resíduos orgânicos. Pesquisa Florestal brasileira, Colombo, n. 54, p. 97-104, 2007.

MARTINS, C. C.; NAKAGAWA, J.; BOVI, M.

L. A.. Efeito da posição da semente no substrato e no crescimento inicial das plântulas de palmitovermelho (Euterpe espiritosantensis Fernandes Palmae). Revista Brasileira de Sementes, v. 21, n. 1, p. 164-173, 1999.

MARTINS, C. C. et al. Efeito do sombreamento e do substrato sobre a germinação e o crescimento de plântulas de Acacia mangium e Acacia mearnsii. Ciência Florestal, v. 22, n., 2, p. 421-431, 2012. NAPPO, M. E. et al. Reflorestamentos mistos com essências nativas para recomposição de matas ciliares. UFLA, Lavras, 2001. p. 5-31. (Boletim Técnico, n. 30).

NASCIMENTO, W. M. O. et al. Influência da posição de semeadura na germinação, vigor e crescimento inicial de plântulas de bacabinha (Oenocarpus mapora Karsten - Arecaceae). Revista Brasileira de Sementes, v. 24, n. 1, p. 179-182, 2002.

NÓBREGA, R. S. A. et al. Utilização de biossólido no crescimento inicial de mudas de aroeira (Schinus terebynthifolius Raddi). Revista Árvore, v. 31, n. 2, p. 239-246, 2007.

RIZZINI, C. T. Árvores e madeiras úteis do Brasil- Manual de dendrologia brasileira. São Paulo: Ed. Edgard Blücher, 1972. 294 p.

SOUSA, A. H. et al. Profundidades e posições de semeadura na emergência e no desenvolvimento de plântulas de moringa. Revista Caatinga, Mossoró, v. 20, n. 4, p. 56-60, 2007. 